Infusion Therapy

Transfusion Medicine

Infusionstherapie

Transfusionsmedizin
Clinical Information · Klinische Information

Infus Ther Transfus Med 2000;27:114-116
Received: March 28, 2000 Accepted: March 29, 2000

\title{
TT Virus
}

\author{
Arbeitskreis Blut, Untergruppe «Bewertung Blutassoziierter Krankheitserreger»
}

\section{Current Knowledge about the Pathogen}

Until now, there have always been patients with liver diseases in whom no markers for the known hepatitis virus infections could be found and who had no history of alcoholism or exposure to other toxic substances ('cryptogenic' hepatitis). At the end of 1997, 'representational difference analysis' (RDA) was used in Japan to isolate a DNA virus from a blood donor who had raised transaminase levels but no serological markers for known hepatitis viruses. From this, a sequence of around 500 nucleotides was cloned [1]. The whole sequence of the TT virus (TTV) genome has now been unravelled [1-3]. The name of this novel virus, TTV, was taken from the initials of the donor from whose serum the virus was isolated, although it is also often interpreted as 'transfusion-transmitted virus'.

\subsection{Characteristics of TT Virus}

The physical and chemical tests performed so far indicate that TTV is a nonenveloped virus with a single-stranded [2], circular DNA genome of negative polarity [3]. According to filtration studies, it appears to have a particle diameter of 30-50 $\mathrm{nm}$. The buoyant density was found to be $1.31-1.34 \mathrm{~g} / \mathrm{ml}$ in $\mathrm{CsCl}(1.26 \mathrm{~g} / \mathrm{ml}$ in sucrose $)$. An electron micrograph is not yet available. The viral genome consists of 3,852 nucleotides and has 2 open reading frames (ORF1 and ORF2) which code for proteins of unknown function, 770 and 202 amino acids in length, respectively. Sequential analyses of a relatively short section showed considerable variability within the TTV genome, as a result of which the virus has now been classified into various genotypes which differ in sequence by more than $30 \%$, each with several subtypes [3-6]. On the basis of the sequences identified so far, a genotyping assay was recently developed using restriction fragment length polymorphism (RFLP) [6].

The biophysical and molecular data available suggest similarities with the Circoviridae family of viruses, previously found in plants and vertebrates (birds and pigs). Because sequence comparisons with all sequences held in genome databases re- vealed no similarities, however, TTV is classified as a member of a new family of viruses, provisionally called the Circinoviridae [3].

\subsection{Infection and Infectious Diseases}

In Japan, TTV DNA was initially identified in the plasma of patients with posttransfusion hepatitis of unknown etiology [1]. On the original assumption that TTV was a parenterally transmissible etiologic agent for hepatitis, the first step was to examine different biopsy samples from patients. TTV DNA could not be identified in the cancerous or noncancerous tissue of patients with hepatocellular carcinoma (HCC) [7]. However, the percentage of TTV-positive patients with $\mathrm{HBV} / \mathrm{HCV}$-associated and non-B, non-C HCC was the same. In some seropositive patients, TTV DNA was also found in stool samples [8,9] and in the saliva [9], but not in the urine [9]. These results suggest that, although TTV can be transmitted via the parenteral route, nonparenteral (e.g. fecal-oral) transmission routes must play a more important role, which might explain the extremely high prevalence rates in people not at increased risk for parenteral infections (see also 1.3).

The virus can be eliminated spontaneously (below the PCR detection limit), but may also persist for several years with no clinical or histopathological evidence of acute or chronic hepatitis. TTV detection associated with raised transaminase levels has only been observed in a few cases. In people who are TTV-positive alone, there are generally no biochemical or histological indicators of hepatocellular destruction [7]. There is as yet no evidence that coinfection with TTV and HBV or HCV has any effect on the course of hepatitis. TTV may be a companion agent with no role (like GBV-C). Intravenous inoculation of chimpanzees with TTV-positive human serum showed that transmission to chimpanzees is possible [3]. However, no biochemical or histological evidence of hepatitis was found. It has therefore not been proven that this novel virus actually plays a role in liver diseases.

No data are currently available on whether the virus can be transmitted sexually. Vertical transmission (mother to child)

\begin{tabular}{ll}
\hline KARGER & @ 2000 S. Karger GmbH, Freiburg \\
Fax +497614520714 & Accessible online at: \\
$\begin{array}{l}\text { E-mail Information@Karger.de } \\
\text { www.karger.com }\end{array}$ & www.karger.com/journals/iut
\end{tabular}


has been recently shown to occur with high efficiency [10]. 46 of 47 newborns from TTV-viremic mothers were TTV-positive from the first sample onward. Furthermore, TTV DNA was found in $74 \%$ of the breast milk samples derived from viremic mothers. Nevertheless, there is no need to refrain from breastfeeding because most children are TTV-viremic even before breastfeeding starts.

\subsection{Epidemiology}

The TT virus is found all over the world. Data on the prevalence of TTV infection must be viewed with caution, as some of the populations analyzed have only been small and methods of DNA detection have not yet been optimized and standardized. As an example, assays based on seminested PCR in the ORF1 region initially prompted reports of TTV prevalence in healthy people (such as blood donors) ranging between $12 \%$ in Japan [2] and the extreme value of $62 \%$ in Brazil [11]. The prevalence of TTV (PCR in ORF1) in patients with various liver diseases and with an increased risk of parenteral transmission is generally slightly higher than in blood donors but still fluctuates considerably. TTV has thus been identified in $12-15 \%$ of patients with cryptogenic cirrhosis, $25-46 \%$ of patients with chronic hepatitis of unknown etiology, and $12.5-21 \%$ of patients with chronic hepatitis C. $19-47 \%$ of patients with fulminant liver failure were found to be TTV DNA-positive prior to orthotopic liver transplantation (OLT) [2, 12]. Following OLT, TTV was identified in $65 \%$ of patients in Germany [13]. The prevalence of TTV is also very high in hemophilia $(68 \%)$ and hemodialysis $(46 \%)$ patients.

The use of new primers from a conserved region of the TTV genome showed that there are probably far more TTV carriers in the healthy population than was originally thought. In Japan, for example, TTV was identified in $92 \%$ of people tested using this system [13] (about 25\% in Germany according to unpublished Robert Koch-Institut data).

\subsection{Detection Methods and Their Significance}

The only way of diagnosing TTV infection at present is to detect the presence of the genome by means of PCR. Until now, this has almost always involved the use of a relatively short sequence of ORF1 for DNA detection and the sequential analysis of various isolates. The efficacy of detection can be improved by optimization of the PCR using conserved regions of the genome (e.g. the 5' end of ORF2). According to endpoint titrations and quantification by means of TaqMan-PCR, the virus load in patient sera seems to be lower in TTV infection than in $\mathrm{HCV}$ and GBV-C infection.

\section{Blood and Plasma Donors}

\subsection{Prevalence and Incidence in Donor Populations}

Early studies showed that the prevalence of TTV infection in Germany was around $7-11 \%$ (or $25 \%$ according to PCR in conserved genome regions) and was the same in men and women. No significant differences in prevalence were observed between healthy donors and donors with raised transaminase levels. The extent to which the degree of fluctuation between countries (1-36\% and $25-92 \%)$ is attributable to geographic differences or differences in the sensitivity/ specificity of the PCR methods used is not clear.

\subsection{Donor Testing and Significance}

In principle, donor blood and plasma can be screened for TTV DNA by means of PCR. As there is no evidence of TTV-associated diseases at present, the significance of positive findings is unclear.

\subsection{Donor Interviews}

On the basis of the data available at present, it is impossible to define risk groups as a basis for health history examinations.

\subsection{Donor Information and Counselling}

On the basis of our current understanding, there is no reason to inform donors if they test positive for TTV.

\section{Recipients}

\subsection{Prevalence and Incidence of Blood-Associated Infections and Infectious Diseases in Recipient Populations}

An early study in the UK revealed that, with the methods used there, $44-56 \%$ of factor VIII and IX concentrate batches tested were TTV-positive. TTV DNA was identified in $27 \%$ of hemophilia patients who had received nonvirus-inactivated preparations, compared with only $5 \%$ of those who had received virus-inactivated concentrates [4] (see also 4.2). The incidence of TTV infection increases with the volume of blood products received.

\subsection{Immune Status (Resistance, Existing Immunity, Immune Response, Age, Exogenous Factors)}

No study results relating to the immune response in people infected with TTV are available at present. There are reports that TTV DNA titers can fall below the detection limit (virus elimination?), but that the virus can also persist for a long period of time [1].

\subsection{Severity and Course of the Disease}

No link has yet been demonstrated between TTV infection and any diseases.

\subsection{Therapy and Prophylaxis}

On the basis of our current understanding, specific prophylaxis or treatment does not appear to be necessary. Retrospective studies of the effect of interferon in patients co-infected with HCV and TTV have demonstrated that TTV was eliminated temporarily in $100 \%$ and permanently in $62.5 \%$ of patients. 
3.5 Transmissibility

See under 1.2.

3.6 Frequency of Administration, Type and Amount of Blood Products

The frequency of TTV detection is higher in multiply transfused patients (e.g. following OLT) and in recipients of nonvirus-inactivated blood products.

\section{Blood Products}

\subsection{Infectious Load of the Starting Material and Test Methods} In view of the high prevalence of TTV DNA among blood donors, it can be assumed that a large proportion of plasma pools will be contaminated with TTV. The virus load in individual plasma is generally low.

\subsection{Methods for Removal and Inactivation of the Infectious Agent}

In a study conducted in the UK [5], TTV DNA was identified more frequently in factor VIII/IX concentrates treated using the solvent-detergent technique than in pasteurized preparations $\left(10 \mathrm{~h}\right.$ at $\left.60{ }^{\circ} \mathrm{C}\right)$.

\subsection{Feasibility and Validation of Procedures for \\ Removal/Inactivation of the Infectious Agent}

The search for suitable model viruses should take into account the fact that, as far as we know, TTV is a nonenveloped virus.

\section{Assessment}

There is as yet no strong evidence of a link between TTV infection and hepatic or extrahepatic disease. On the basis of the data currently available, TTV is a virus which occurs all over the world and which is transmissible via the parenteral route. However, its high prevalence among the healthy population suggests that other routes of transmission such as the oral-fecal route play an important role. The identification of TTV DNA in the stool may be evidence of a fecal-oral transmission mechanism. Further studies are required to investigate the clinical significance of this novel virus.

This paper was completed on September 22, 1999, and approved by the German Advisory Committee Blood (Arbeitskreis Blut) on November 16, 1999. It was compiled by the members of the subgroup 'Assessment of Pathogens Transmissible by Blood' of the German Advisory Committee Blood (Arbeitskreis Blut):

Prof. Dr. Reinhard Burger Prof. Dr. Wolfram Gerlich Prof. Dr. Lutz Gürtler

Dr. Margarethe Heiden

Dr. Walter Hitzler

Prof. Dr. Bernd Jansen

Dr. Hans Lefèvre

Prof. Dr. Johannes Löwer

Prof. Dr. Wolf-Dieter Ludwig

Dr. Thomas Montag-Lessing

Dr. Arnold Paessens

Prof. Dr. Georg Pauli

Prof. Dr. Rainer Seitz

Dipl.-Med. Uwe Schlenkrich

Dr. Edgar Werner

Dr. Hannelore Willkommen

with the collaboration of PD Dr. Eckart Schreier and Dr. Marina Höhne of the Robert Koch-Institut

\section{References}

1 Nishizawa T, Okamoto H, Konishi K, Yoshizawa H, Miyakawa Y, Mayumi M: A novel DNA virus (TTV) associated with elevated transaminase levels in posttransfusion hepatitis of unknown etiology. Biochem Biophys Res Commun 1997;241:92-97.

2 Okamoto H, Nishizawa T, Kato N, Ukita M, Ikeda H, Jizuka H, Miyakawa Y, Mayumi M: Molecular cloning and characterization of a novel DNA virus (TTV) associated with posttransfusion hepatitis of unknown etiology. Hepatol Res 1998;10:1-16.

3 Mushahwar IK, Erker JC, Muerhoff AS, Leary TP, Simons JN, Birkenmeyer LG, Chalmers ML, PilotMatias TJ, Desai SM: Molecular and biophysical characterization of TT virus: Evidence for a new virus family infecting humans. Proc Natl Acad Sci USA 1999;96:3177-3182.

4 Höhne M, Berg T, Müller AR, Schreier E: Detection of sequences of TT virus, a novel DNA virus, in German patients. J Gen Virol 1998;79: 27612764
5 Simmonds P, Davidson F, Lycett C, Prescott LE, MacDonald DM, Ellender J, Yap PL, Ludlam CA, Haydon GH, Gillon J, Jarvis LM: Detection of novel DNA virus (TTV) in blood donors and blood products. Lancet 1998;352:191-195.

6 Tanaka Y, Mizokami M, Orito E, Ohno T, Nakano T, Kato T, Kato H, Mukaide M, Park YM, Kim BS, Ueda R: New genotypes of TT virus (TTV) and genotyping assay based on restriction fragment length polymorphism. FEBS Lett 1998;437:201206

7 Yamamoto T, Kajino K, Ogawa M, Gotoh I, Matsuoka S, Suzuki K, Moriyama M, Okubo H, Kudo M, Arakawa Y, Hino O: Hepatocellular carcinomas infected with the novel TT DNA virus lack viral integration. Biochem Biophys Res Commun 1998, 251:339-343.

8 Okamoto H, Akahane Y, Ukita M, Fukuda M, Tsuda F, Miyakawa Y, Mayumi M: Faecal excretion of a nonenveloped DNA virus (TTV) associated with posttransfusion non-A-G hepatitis. J Med Virol 1998;56:128-132.
9 Ross RS, Viazov S, Runde V, Schaefer UW, Roggendorf M: Detection of TT virus DNA in specimens other than blood. J Clin Virol 1999;12: 1-4

10 Schröter M, Polywka S, Zöllner B, Schäfer P, Laufs R, Feucht HH: Detection of TT virus DNA and GB virus type $C$ /hepatitis $G$ virus RNA in serum and breast milk: Determination of mother-to-child transmission. J Clin Microbiol 2000;38:745-747.

11 Niel C, de Oliveira JM, Ross RS, Gomes SA, Roggendorf M, Viazov S: High prevalence of TT virus infection in Brazilian blood donors. J Med Virol 1999;57:259-263.

12 Berg T, Schreier E, Heuft HG, Höhne M, Bechstein WO, Leder K, Hopf U, Neuhaus P, Wiedenmann B: Occurrence of a novel DNA virus (TTV) infection in patients with liver diseases and its frequency in blood donors. J Med Virol 1999;59:117-121.

13 Takahashi K, Hoshino H, Ohta Y, Yoshida N, Mishiro S: Very high prevalence of TT virus (TTV) infection in general population of Japan revealed by a new set of PCR primers. Hepatol Res 1998; 12:233-239. 